\title{
FORCE PRODUCTION DURING ESCAPE RESPONSES: SEQUENTIAL RECRUITMENT OF THE PHASIC AND TONIC PORTIONS OF THE ADDUCTOR MUSCLE IN JUVENILE SEA SCALLOP, PLACOPECTEN MAGELLANICUS (GMELIN)
}

\author{
PIERRE-GILDAS FLEURY,${ }^{1}$ XAVIER JANSSOONE, ${ }^{2}$ MADELEINE NADEAU ${ }^{3}$ AND \\ HELGA GUDERLEY ${ }^{2}$ * \\ 'IFEMER, Laboratoire Environnement Ressources, 56470 La Trinité/mer, France; ${ }^{2}$ Université Laval, \\ Dép. de biologie, Québec, P.Q. Canada GIK 7P4; ${ }^{3} M A P A Q$, Direction de la Recherche Scientifique et \\ Technique, Cap aux Meules, P.Q. Canada GOB IBO
}

\begin{abstract}
Giant scallops, Placopecten magellanicus, respond to the presence of starfish predators with an escape response consisting of a series of rapid valve adductions that allow the scallop to jump or swim away from the predator. To evaluate the coordination of the activity of the tonic and phasic muscles during such escape responses, we recorded their force production by attaching a force gauge to the shell of intact scallops and then stimulating the scallops with starfish. These recordings showed series of phasic contractions (claps) separated by prolonged tonic contractions. Numerous characteristics could be quantified from these recordings including the maximal force, mean force during the first minute, force, frequency and number of claps per series, as well as the force and duration of tonic contractions. The number of claps per series declined and the duration of the tonic contractions increased as the escape response continued. For most scallops, phasic and tonic contractions produced similar levels of force that changed little during the escape responses. The alternation between phasic and tonic contractions suggests that periods of tonic contraction allow the phasic muscle to recuperate and facilitate subsequent phasic contractions. Principal component analysis (PCA) confirmed the coordination between the phasic and tonic adductor muscles, because characteristics of each type of contraction, were closely associated. This method combines the advantages of stimulation of scallops by their predators with the simplicity of force gauge measurements. Force production during escape responses by individual scallops was highly reproducible, suggesting these measurements have considerable potential for tracking changes in the physiologic status of giant scallops.
\end{abstract}

KEY WORDS: force production, muscle contraction, escape response, tonic muscles, Placopecten magellanicus, scallop

\section{INTRODUCTION}

Scallops possess a stereotypic escape response that allows them, through a series of rapid valve adductions or claps, to jump or swim away from their predators. This response relies on contraction of the adductor muscle that works in opposition to the hinge ligament, the action of which is to separate the valves. The literature consensus is that claps are produced by contractions of the large phasic portion of the adductor muscle, whereas slow movements and maintenance of a given shell opening are achieved by the contraction of the smaller tonic portion (Chantler 1991, Wilkens 1981). Beyond its role in controlling the movements of the shell, the adductor muscle plays a central role in the storage of energetic reserves. The concentration of muscle glycogen changes considerably during the reproductive cycle of most scallops (Brokordt \& Guderley 2004a) and muscle protein levels may decrease if environmental food availability is inadequate to support gametogenesis. The mobilization of muscle glycogen to support the energetic requirements of other tissues has led to the suggestion that muscle glycogen levels reflect the energetic condition of scallops (Fleury et al. 1996, Maguire et al. 1999). As performance of repeated escape responses is reduced during gametogenesis and after spawning in Chlamys islandica and Euvola ziczac (Brokordt et al. 2000a, Brokordt et al. 2000b), mobilization of muscle macromolecules seems to compromise scallop performance. Effectively, the simultaneous changes in the levels of glycogen and in the activities of glycolytic enzymes in the adductor muscle may be linked with the decreased capacity to repeat escape responses (Brokordt et al. 2000a,b; Brokordt \& Guderley 2004b). This suggests, in turn, that escape response capacities may reflect the physiologic status of scallops.

*Corresponding author. helga.guderley@bio.ulaval.ca
Evaluation of the contractile performance in scallops has been carried out in 2 complementary fashions: quantification of the escape response by observation of the performance of the intact scallop (visual observations, video-recording or pressure measurements) and measurement of the contractile properties of isolated fibers from the phasic adductor muscle. During quantification of escape responses, scallops are stimulated with their predator and the number and frequency of claps as well as the duration of the response are measured (e.g., Manuel \& Dadswell 1991, Legault \& Himmelman 1993, Barbeau \& Scheibling 1994, Brokordt et al. $2000 \mathrm{a}$, Brokordt et al. 2000b). The mechanical performance of the adductor muscle during escape responses has also been monitored by sonomicrometric evaluation of the length of the adductor muscle coupled with a pressure sensor near the hinge (Marsh et al. 1992). These high-resolution measurements during swimming by Argopecten irradiens concentricus indicate the length changes and the power produced by the adductor muscle (Marsh et al. 1992). The contractile properties of the striated phasic adductor muscle measured in vitro are typical of a fast muscle, with speeds of contraction and tensions similar to those of vertebrate fast glycolytic fibers (Olson \& Marsh 1993). When the in vivo length changes are used to evaluate contractile properties in vitro, it is apparent that the muscle does not operate on the isotonic force velocity curve (Marsh \& Olson 1994). These approaches provide considerable insight into the working of the phasic adductor muscle, but the co-ordination of the tonic and phasic portions of the muscle during activity by scallops remains little known. Repeated clapping leads to accumulation of anaerobic end-products in the phasic and tonic portions of the adductor muscle of Placopecten magellanicus (de Zwaan et al. 1980), suggesting participation of both portions during extensive clapping activity.

The power produced and the energetic cost of activity by the two sections of the adductor muscle differ considerably. The rapid 
contractions of the phasic portion permit it to generate more power than can be achieved by the slow contractions of the tonic muscle. However, the phasic portion requires high rates of ATP generation to produce tension, whereas most of the tension produced by the tonic portion is generated by the catch mechanism. Phasic contractions are primarily supported by generation of ATP from arginine phosphate through the arginine kinase reaction, with only $30 \%$ of the ATP used during exhaustive escape responses arising from anaerobic glycolysis and octopine generation (de Zwaan et al. 1980, Livingstone et al. 1981, Chih \& Ellington 1983, Chih \& Ellington 1986). Fatigue from extensive phasic contractions seems related to decreases in the free energy change of ATP hydrolysis with repeated contractions (Bailey et al. 2003). Catch allows prolonged contraction at little metabolic cost, but only allows limited movement.

Measurements of muscle strength using a force gauge have been proposed as a means of testing the vitality of scallops (Fleury et al. 1997). This approach records the force that can be maintained by the valves of scallops. The rapidity of force production indicates whether it originates in the phasic or tonic portions of the adductor muscle. Here we report an approach in which a force gauge is used to monitor force production by juvenile giant scallops (Placopecten magellanicus (Gmelin)) during escape responses from starfish. Essentially, the valves of the scallop are maintained open at a distance similar to that used during routine respiration, one valve is fixed to the test stand and the other is connected to the force gauge. The mantle of the scallop is then stimulated with the starfish (Asterias vulgaris) and the contractions of the adductor muscle produce changes in force that are continually monitored. Phasic contractions are apparent as rapid peaks, whereas tonic contractions cause gradual changes in force that can be maintained for prolonged periods. We compared the characteristics of the escape response measured by the force gauge with those determined by visual observation of escape responses of unrestrained scallops. We also assessed whether individual differences in force production were reproducible.

\section{MATERIAL AND METHODS}

\section{Scallop Holding Conditions}

Juvenile Placopecten magellanicus (shell height $46.1 \pm 2.3$ $\mathrm{mm}$ ) were obtained from Petoncles 2000 (Cap aux Meules, les Iles de la Madeleine, P.Q. Canada) and held in pearl nets in the nearby Lagune de Havre aux Maisons until approximately 2 weeks before use. They were then brought to the MAPAQ wet laboratory at Havre aux Maisons where they were held in running seawater pumped from the lagoon. During the measurements using the force gauge, water temperature was approximately $6^{\circ} \mathrm{C}$ whereas during the behavioral observations of escape responses, water temperature was approximately $9.5^{\circ} \mathrm{C}$. Salinity was $32 \%$ o throughout the experiments. Before measurements using the force gauge, scallops were individually identified with tags (Hallprint) that were attached with cyanoacrylic glue. The scallops were left to recuperate for several days after tagging. Asterias vulgaris (Verrill) $(70 \mathrm{~mm})$ were obtained from local fisherman and were maintained in separate holding tanks for several weeks. Starfish were fed with mussels once weekly.

\section{Behavioral Observations of the Scallop Escape Response}

These tests followed the method used by Lafrance et al. 2002, except that the tanks in which the escape responses were measured contained $40 \mathrm{~L}$ and the water temperature was $9.5^{\circ} \mathrm{C}$. The scallops were stimulated until no further claps were elicited by the touch of an Asterias arm during $1 \mathrm{~min}$. We measured the total number of claps, the maximal number of claps per series, and the duration of the response. We calculated the mean clapping frequency by dividing the total number of claps by the time elapsed between the start of the test and the last clap.

\section{Measurements of Force Generation During Escape Responses}

During transfer of the scallops from the holding tanks to the test stand, the experimenters maintained the valves shut. The valves of the scallops were then placed between a flat hook protruding from the manual test stand (Mecmesin test stand Hersham, West Sussex, England www.mecmesin.com) and a similar hook protruding from the extension of the force gauge (Mecmesin Advanced Force Gauge, AFG-250N). Hereafter this will be called the muscle meter. The scallops $(n=20)$ were in air during the test. The manual test stand was adjusted to separate the valves (Fig. 1) by a distance similar that observed in resting scallops ventilating normally. For our scallops, the separation was approximately $16 \mathrm{~mm}$, an angle of $20^{\circ}$ (Table 1). Scallops could, by opening their valves further, detach themselves from the hooks, but this occurred infrequently. Once positioned on the muscle meter, the scallops were continually stimulated with an arm of the seastar, Asterias vulgaris, during $200 \mathrm{~s}$. Instead of ending the recordings after a given time without a clap as during our behavioral observations (see earlier), we used a fixed duration of testing. Recordings from the force transducer were taken at a frequency of $10 \mathrm{~Hz}$ and stored on an IBM personal computer using Data Plot $(1.03,1997)$ before transfer to spread sheets for graphical presentation and analysis of the patterns of force generation (see results). To evaluate the reproducibility of these measurements, scallops were tested one day, returned to their holding tanks and the second test was carried out $2-3$ days after the first test.

\section{Statistical Analysis}

As each scallop was measured twice on the force gauge, we compared the first and second values of the various characteristics to assess the repeatability of the estimates, using paired $t$-tests, with an $\alpha$ of 0.05 . Statistical comparisons were done with JMP IN (SAS). Principal components analysis of these characteristics as well as ANOVAs and a posteriori comparisons (Newmann \& Keuls) of the responses during the different series were carried out using XLSTAT 7.1. (Société Addinsoft) http://www.xlstat.com

\section{RESULTS}

\section{Characteristics of the Force Recordings During Escape Responses}

Scallops responded to having their valves separated by the muscle meter by resisting further opening. This was indicated by an increase in force production. At the first resistance provided by the scallop, the experimenter stopped increasing the separation between the valves and maintained the opening at a distance typical of resting scallops. Continual stimulation with the seastar elicited a typical response by the scallops (Fig. 2). Almost all scallops reacted immediately to this stimulation with a rapid series of claps, followed by a tonic contraction. This tonic contraction was generally followed by another series of claps, and then again by a tonic contraction. Some scallops managed to carry out 7 series of claps, separated by tonic contractions, during the $200 \mathrm{~s}$ measurement 

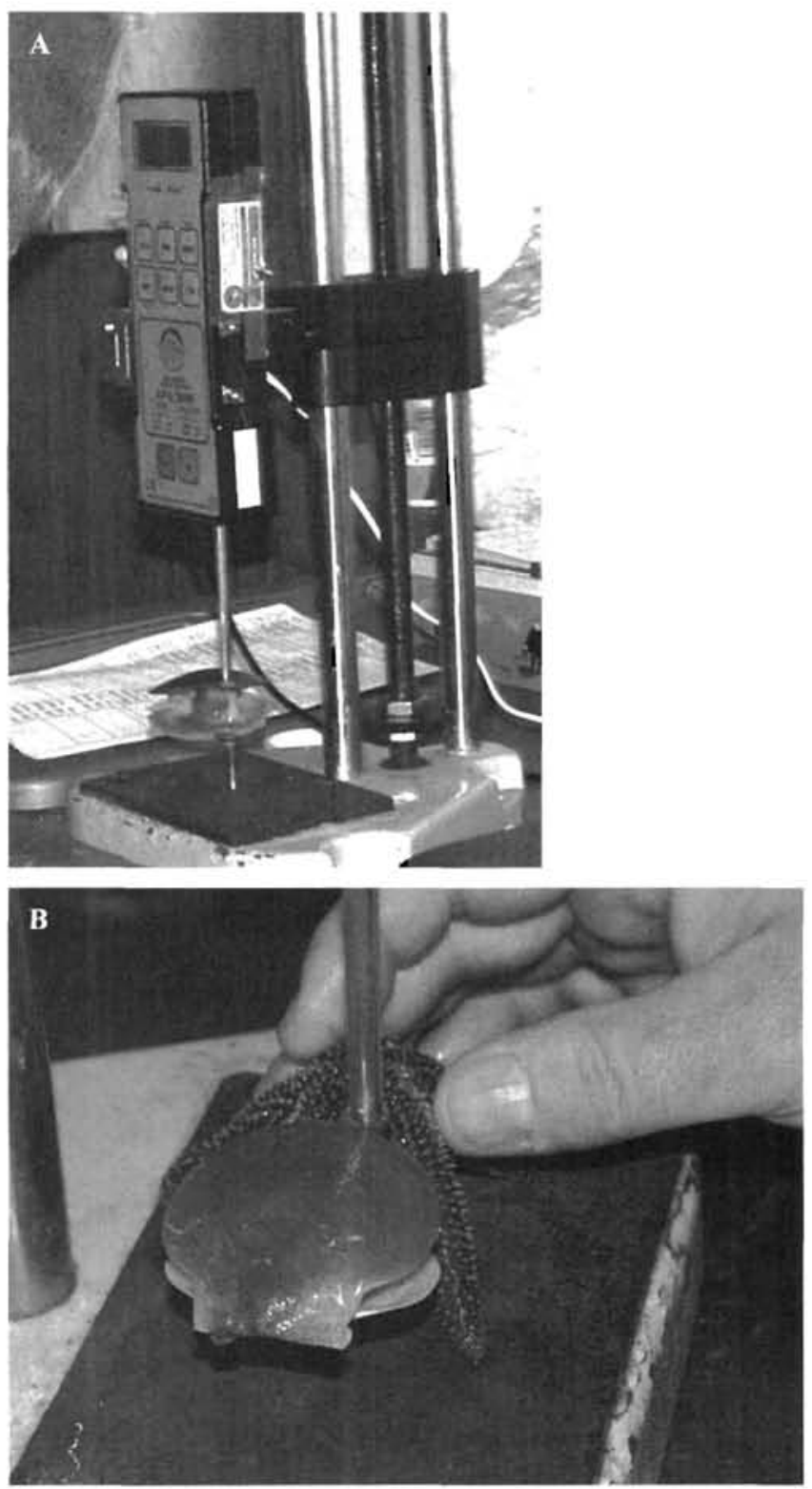

Figure 1. Force gauge on its test stand with a scallop in position for force measurements. Scallop (Placopecten magellanicus) on force meter being stimulated with a starfish (Asterias vulgaris)

period. Occasionally scallops made exceptionally strong claps, with a force change that was more than twice that of the average clap.

\section{Analysis of Force Recordings}

To analyze these force recordings, we evaluated a variety of characteristics: maximal force (Fmax), mean force during the first minute of stimulation $(\mathrm{Fm} / \mathrm{n})$, number of series of claps (Nps), number of tonic contractions (Ntc), number of claps per series of claps ( $\mathrm{Npc1}, \mathrm{Npc} 2, \mathrm{Npc} 3 \mathrm{etc})$ mean force change per series of claps (Fpcm1, Fpcm2, Fpcm3 etc), clapping rate during each series (rpcl, rpc2, rpc3 etc), force change and duration of the tonic contractions (Ftcl, Ftc2, Ftc3, etc and Dtc1, Dtc2, Dtc3 etc, respectively), maximum number of claps per series ( $\mathrm{Npc}$ max), mean clapping rate (rpcm) and total number of claps(Npctot). We also noted when tonic contractions were continuing at the end of a recording and the mean basal force present throughout the recording. This basal force was subtracted from the force values to obtain the force developed during the phasic and tonic contractions.

An alternation between series of claps and individual tonic contractions was present in all the recordings examined (Fig. 2). The alternation was reflected in the fact that the number of series of claps was practically identical to the number of tonic contractions (Table 1). Typically the maximal number of claps occurred during the first series and was equivalent to approximately half of the claps made by the scallop during the escape response (Fig. 3, Table 1). In these tests, the last clap occurred after approximately 2 min of stimulation. The clapping rate in the different series varied less than the number of claps per series, but both decreased as the escape response progressed, particularly during the first test (Fig. 3). The decrease in clapping rate was particularly pronounced when scallops made more than 4 series of claps in $200 \mathrm{~s}$, (data not shown). The shortest interval between successive claps consistently occurred at the start of the escape responses, leading to a maximal clapping frequency of 1.2 claps s$^{-1}$. Whereas the claps in the first series tended to be the strongest, the mean increase in force changed little during successive series of phasic contractions (Fig. 3).

The duration of tonic contractions increased as the escape response progressed (Fig. 3). In fact most escape response tests ended with an extended tonic contraction that was not finished at the end of the $200 \mathrm{~s}$ recording period. The increase in force during the tonic contractions was similar to the force increase during claps and changed little as the escape response progressed (Fig. 3). An exceptional scallop ( 1 of 20 , interestingly the only one with albino pigmentation) showed limited development of tonic force between the series of claps.

In spite of the underlying alternation between phasic and tonic contractions, the two portions of the muscle contracted simultaneously during at least a portion of many escape responses (Fig. 2). Such simultaneous contractions typically occurred during decreases in tonic force production.

\section{Principal Components Analysis}

The force recordings generated many parameters, some of which may reflect similar underlying phenomena. To evaluate links among the parameters, we applied a principal components analysis to these data. The first axis, defined primarily by the rates of clapping and the total number of claps, explained $30 \%$ of the variability in the data. Force values were centrally positioned in this plot. The second axis explained $27 \%$ and the third explained $17 \%$ of the variability. On the plot generated by the first two axes (Fig. 4), the close positioning of the number of tonic contractions (Ntc) and the number of series of claps (Nps) reflected that series of claps are separated by tonic contractions. Similarly, the maximal force generated by phasic contractions (Fpcmax) and the mean force generated during the first minute $(\mathrm{Fm} / \mathrm{n})$ were closely positioned. The data obtained during successive series (rates of phasic contractions ( $\mathrm{rpcl}-3$ ), duration of tonic contractions (dtc 1-3), force of tonic contractions (ftc I-3), number of phasic contractions (Npc 1-3) and rate of phasic contractions (rpc I-3) were consistently found in similar sections of the PCA plot.

\section{Repeatability of Force Recording During Escape Responses}

When escape responses were repeated within $72 \mathrm{~h}$ on the same scallops, virtually all aspects of the escape responses remained 
TABLE 1

Characteristics of force production and contractile patterns during escape responses of juvenile Placopecten magellanicus, shown as $\mathbf{X} \pm$ s.d. The two series of measurements were separated by at least $48 \mathrm{~h}$ of recuperation in running seawater. The $P$ value indicates the probability that the values differed (paired $t$-tests). The codes given after the name of each variable are those shown in the plot of the principal components analysis.

\begin{tabular}{|c|c|c|c|}
\hline & 1st Measurement & 2nd Measurement & $P$ \\
\hline Number of series of claps (Nps) & $3.7 \pm 1.5$ & $4.2 \pm 1.5$ & .166 \\
\hline Number of tonic contractions ( $\mathrm{Ntc}$ ) & $3.55 \pm 1.6$ & $4.17 \pm 1.5$ & .085 \\
\hline Maximum force, $\mathrm{N}$ (Fmax) & $3.93 \pm 1.01$ & $3.88 \pm 0.71$ & 0.83 \\
\hline Basal force, $\mathrm{N}(\mathrm{Fb})$ & $1.22 \pm 0.68$ & $0.75 \pm 0.40$ & 0.02 \\
\hline Total net force $1 \mathrm{st} \min , \mathrm{N}(\mathrm{Fm} / \mathrm{n})$ & $0.87 \pm 0.44$ & $0.96 \pm 0.32$ & 0.48 \\
\hline Maximum claps/series (Npc max) & $9.35 \pm 5.5$ & $7.7 \pm 3.3$ & 0.25 \\
\hline Total number of claps (Npc tot) & $18.6 \pm 7.4$ & $18.5 \pm 5.2$ & 0.94 \\
\hline Time of last clap (tlpc) & $118 \pm 43$ & $126 \pm 38$ & 0.49 \\
\hline Overall clapping rate, claps $\mathrm{s}^{-1}$ & $0.17 \pm 0.09$ & $0.16 \pm 0.05$ & 0.46 \\
\hline Shortest interval between two claps, $s$ & $1.00 \pm 0.43$ & $1.02 \pm 0.37$ & 0.96 \\
\hline Highest clapping rate, claps $\mathrm{s}^{-1}$ (rpc max) & $1.22 \pm 0.60$ & $1.14 \pm 0.51$ & 0.73 \\
\hline Time of last clap, s (tlpc) & $118 \pm 43$ & $126 \pm 38$ & 0.49 \\
\hline Opening angle $\left(^{\circ}\right)(\mathrm{Op})$ & $17.75 \pm 2.22$ & $13.00 \pm 1.73$ & 0.09 \\
\hline
\end{tabular}

unchanged (Table 1; Fig. 2, 3). Both the values of the different parameters and the change in these values as the escape test progressed were similar between the two tests. The maximal force, mean force during the first minute, number of series of claps, number of tonic contractions, maximum claps per series, total number of claps, time of last clap, overall clapping rate, shortest interval between successive claps and highest clapping rate did not differ in these measurements (Table 1, paired $t$-tests). The changes of the clapping frequency, tonic and phasic force production, duration of tonic contractions and the number of claps per series as the escape response progressed also did not differ between the first and second tests (Fig. 3). Only the force change during claps was somewhat higher during the second escape tests, but this was only significant during the first series of claps.

\section{Comparison of Force Recordings With Behavioral Observations of Escape Responses}

When the escape responses of unrestrained juvenile Placopecten were tested in aquaria following our standard protocol, the maximal number of claps per series $(8 \pm 3.7)$ was similar to the values obtained using the muscle meter. The mean rate of clapping $\left(0.167 \pm 0.07\right.$ claps s $\left.^{-1}\right)$ was the same as the rates observed on the muscle meter. This similarity is even more interesting in light of the fact that these behavioral observations were made at a slightly warmer temperature $\left(9.5^{\circ} \mathrm{C}\right.$ vs. $\left.6^{\circ} \mathrm{C}\right)$ than the force measurements. On the other hand, the total number of claps was twice that on the muscle meter $(39 \pm 12)$, and the duration of the clapping response $(4.2 \pm 1.9 \mathrm{~min})$ was greater than the time at which the last clap was observed using the muscle meter (Table 1). As the tests with unrestrained scallops were carried out in water, the scallops could "chose" the opening of their valves and their rate of ventilation, perhaps their escape responses could last longer and include more claps.

\section{DISCUSSION}

In nature, force production by the scallop adductor muscle leads to slow movements adjusting the opening of the valves during tonic contractions or to rapid movements, in the form of jumps or swims, taking the scallop away from a potential predator. For a scallop confined to a force transducer and being touched by a "seastar" the need for a response would seem more intense. Nonetheless, the frequency of claps and the maximal number of claps in a series were similar to values observed during visual observation of escape responses and to those obtained at $12^{\circ} \mathrm{C}$ for escape response tests carried out on similarly sized juvenile Placopecten (Lafrance et al. 2002). On the other hand, the total number of claps and the duration of claps were lower in our measurements on the muscle meter. This difference may be caused by the fact that the muscle meter tests were carried out in air. However, the similarity of the clapping rates and of the maximal number of claps in a series suggests that the basic patterns of muscle contraction did not differ in the two types of tests.

The most dramatic pattern we observed in these experiments was the alternation between phasic and tonic contractions. We suggest that the tonic contractions may represent a mechanism whereby the phasic muscle is given time to recuperate from its rapid contractions. Contractions by the striated adductor muscle primarily use ATP generated from arginine phosphate by the arginine kinase reaction (Chih \& Ellington 1983, Thompson et al. 1980, Bailey et al. 2003). The phasic adductor muscle in resting scallops contains high levels of arginine phosphate (typically 30 mM; (Livingstone et al. 1981, Chih \& Ellington 1983, Bailey et al. 2003), but these only suffice to support a limited number of contractions. Anaerobic glycolysis cannot provide ATP at rates that are as rapid as those provided by the arginine kinase reaction. The activity of arginine kinase in the phasic adductor muscle of Placopecten was approximately $2500 \mathrm{I} . \mathrm{U} . \mathrm{g}^{-1}$ wet mass whereas that of octopine dehydrogenase was only 60 I.U. $\mathrm{g}^{-1}$ wet mass (Janssoone \& Guderley, unpublished). Such relative values are also found in Chlamys islandica and Euvola ziczac (Brokordt et al. 2000a, Brokordt et al. 2000b). Recovery of the phasic muscle could occur through production of ATP by oxidative phosphorylation or by anaerobic glycolysis. This ATP would then be used to reconvert arginine to arginine phosphate. The use of anaerobic glycolysis is analogous to the mechanism proposed to occur during the valve closure that follows exhausting escape responses in some scallops (e.g., large Placopecten, Chlamys islandica, Pecten maximus; Gade et al. 1978, de Zwaan et al. 1980, Livingstone et al. 


\section{First recordings}

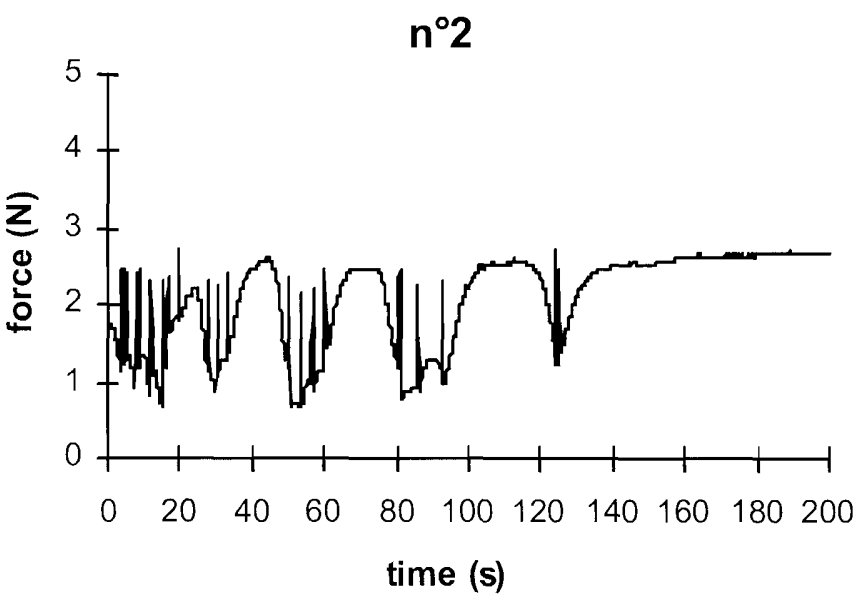

Second recordings

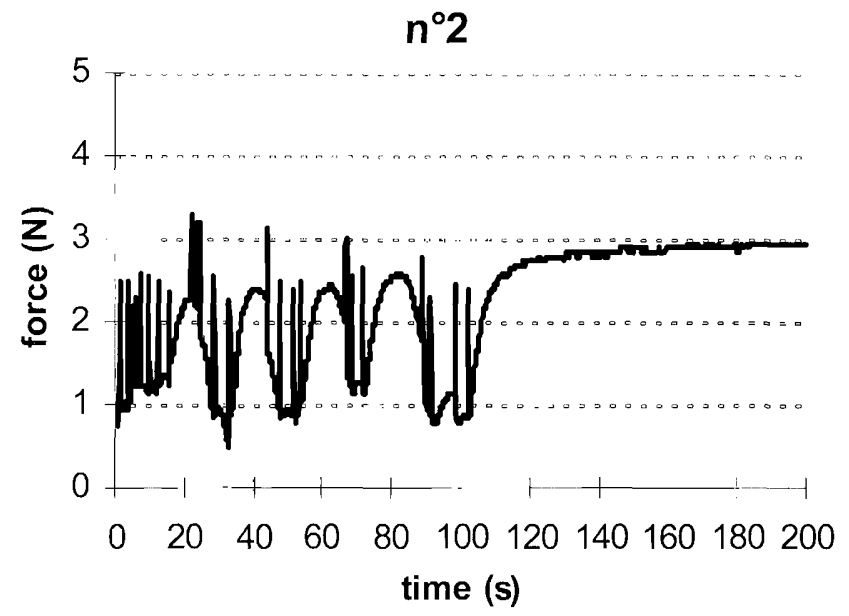

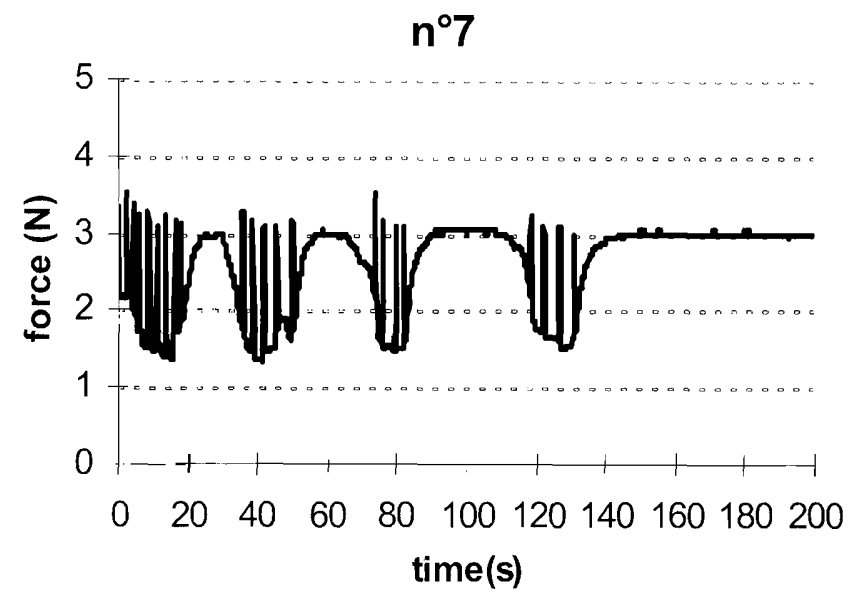

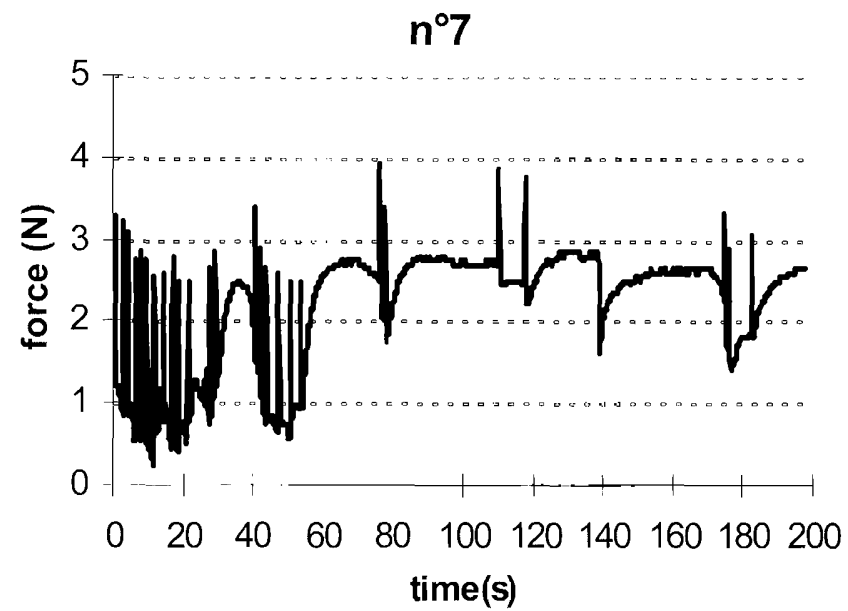

Figure 2. First and second force recordings during escape responses by two juvenile Placopecten. Sustained force increases were considered to be tonic contractions whereas the sharp peaks were considered to be phasic contractions. Force recordings were separated by $48-72$ h.

1981, Bailey et al. 2003). The difference is that we propose this is occurring during the pauses between claps in the escape response. In a natural escape response an increase in tonic tension would protect the scallop against the predator by decreasing the separation between the valves. That the duration of tonic contractions tends to increase during the escape response speaks to increasing fatigue of the phasic muscle perhaps because of decreases in the free energy change of ATP hydrolysis (Bailey et al. 2003).

Phasic and tonic contractions developed similar levels of force in these tests, although some individuals made extremely strong claps. Whereas contraction frequency and duration changed as the escape responses progressed, tension development remained stable. For an individual muscle, tension development in a given stimulation regimen is a direct function of sarcomere length. Optimal overlap between thin and thick filaments in phasic muscle occurs at the valve separation maintained during routine ventilation (Marsh \& Olson 1994). The similarity of force development during successive phasic contractions is compatible with the suggestion that scallops do not stretch their adductor muscle much beyond the length allowing optimal sarcomere length before ini- tiating contractions. The overall similarity of force development during phasic and tonic contractions is intriguing particularly as the striated adductor is considerably larger than the smooth adductor. This speaks to the greater efficiency of the tonic contractions. The exceptional, extremely strong claps shown by a few individuals may correspond to multiple stimulation leading to summation of force development.

Although our technical approaches differed considerably, the highest clapping frequency obtained in our recordings is close to the values presented by Marsh \& Olson (1994) for Argopecten irradians. Using sonomicrometry to assess the length change of the adductor muscle during swimming of scallops in vivo, they show the interval between successive claps to be $0.6 \mathrm{~s}$. This gives

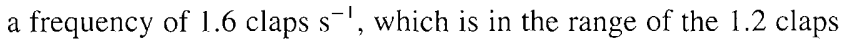
$\mathrm{s}^{-1}$ we found for Placopecten. Considering that these values were obtained with different species and at different temperatures $(6.5$ vs. $10^{\circ} \mathrm{C}$ ), the agreement is good. This rate may be limited by the capacity of myosin ATPase to achieve sarcomere shortening as well as the capacity for $\mathrm{Ca}^{++}$uptake by the sarcoplasmic reticulum. In our recordings, the highest frequencies of contraction occurred 

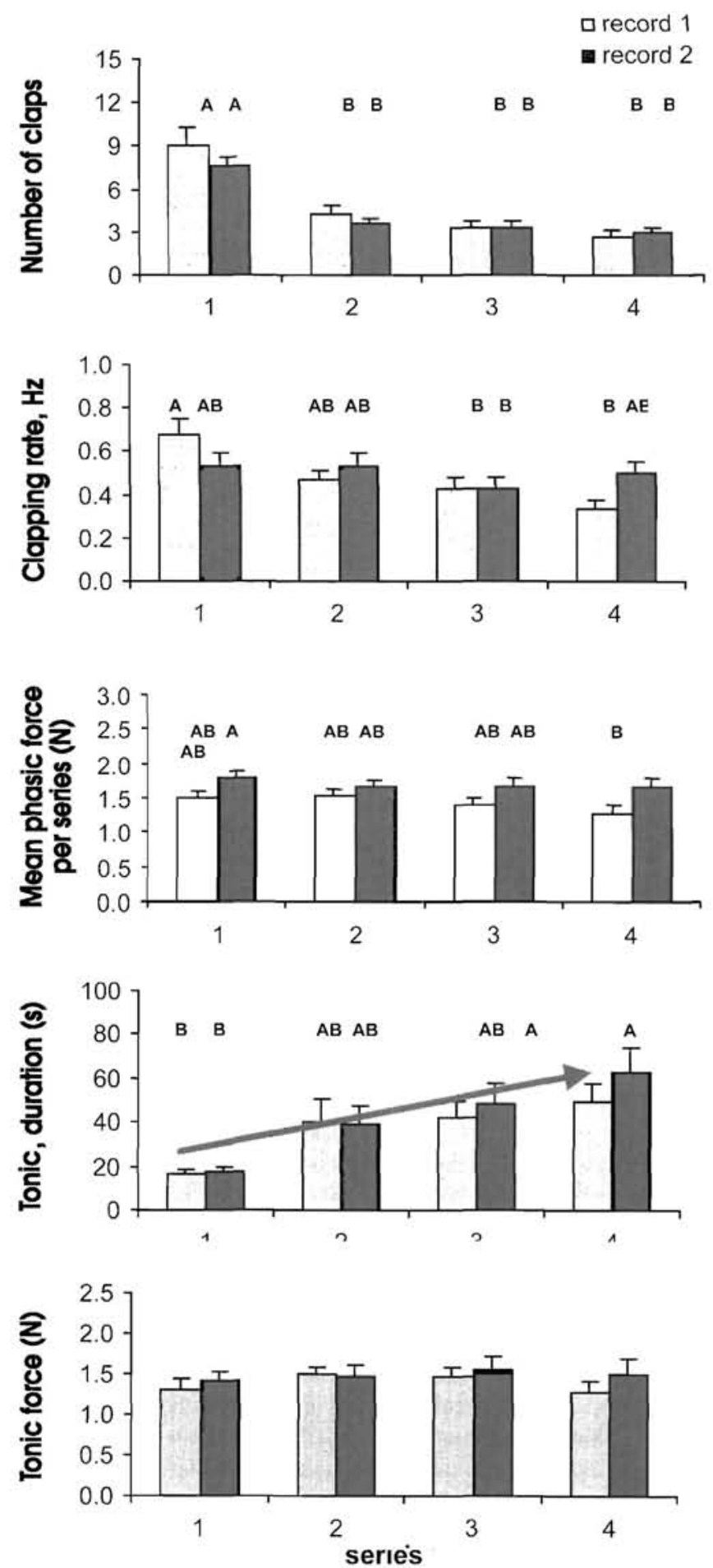

Figure 3. Changes in number of claps, clapping rate, mean phasic force per series of claps and in the duration and force of successive tonic contractions during the first and second recordings of force production during escape responses of Placopecten magellanicus. When two columns share a letter, they do not differ (ANOVA followed by $a$ posteriori multiple comparisons).

at the beginning of the escape responses, both when assessed as the interval between successive claps and the overall frequency per series of claps. The highest clapping rate is approximately twice the highest rate sustained during a series. The reduction in clapping

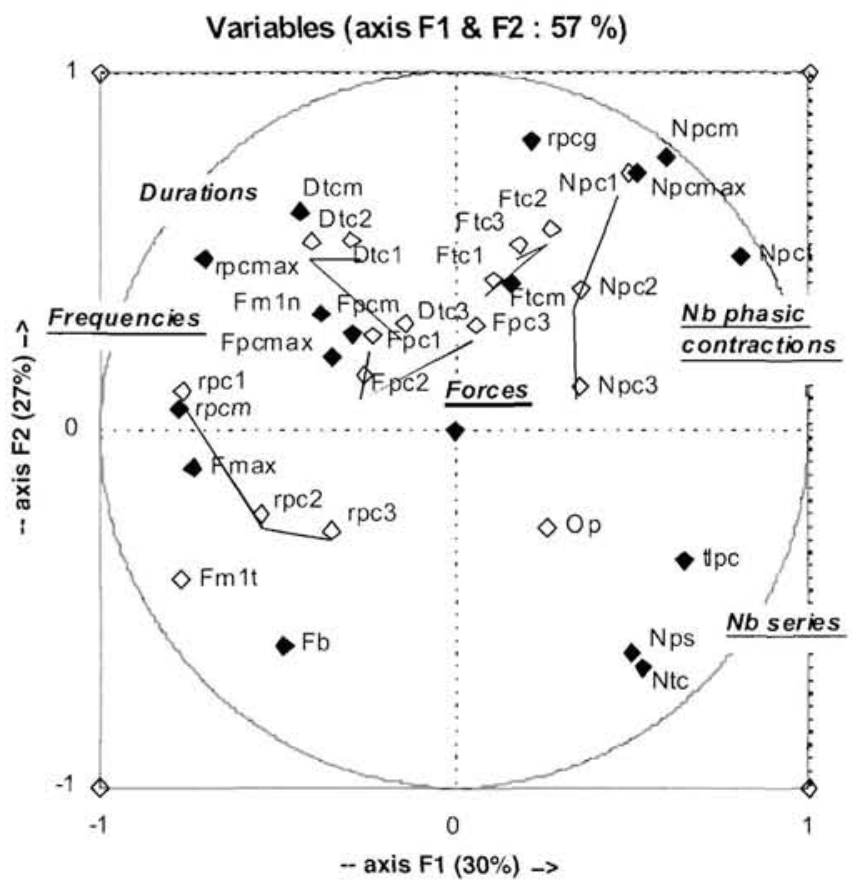

Figure 4. Relationships revealed by the first two axes of the principal components analysis of the overall characteristics of the force recordings during escape responses of Placopecten magellanicus.

frequency and force production as the escape responses progressed is in agreement with the fatigability of the phasic adductor muscle identified by Olson \& Marsh (1993). The agreement of our maximal clapping rates with those obtained using radically different approaches gives further support to the validity of our force recordings as a means of assessing the performance of the scallop adductor muscle.

Use of a force meter to assess muscle performance is a technically simple, fairly inexpensive and portable approach. Positioning a scallop for a force measurement takes little time and does not injure the animal. The animal can be studied directly after being positioned on the test stand. Stimulation of the scallop with its predator is an efficient means of eliciting phasic and tonic adductions. Tonic contractions are virtually impossible to assess during visual observations of escape responses. The equipment required can easily be transported to remote locations, although electricity is required for the operation of our force gauge. These advantages coupled with the high precision of the data recording make this a highly promising method for evaluating the vitality of scallops or establishing the impact of treatments used during culture or the impact of cycles in food availability or reproductive investment. Monitoring a dynamic behavior such as the scallop escape response from a predator using the muscle meter provides considerably more information than available through direct observation of an escape response and is much less invasive than the implantation of electrodes and pressure gauges. Furthermore, because $99 \%$ of the work during scallop swimming is used to form propulsive jets (Cheng et al. 1996), a stationary animal will have similar energy expenditures for valve adductions as a mobile animal. Finally, our results show that this technique is reproducible and provides values for muscle performance characteristics that are similar to those given by other, much more invasive, techniques. 


\section{ACKNOWLEDGMENTS}

The authors thank Bruno Myrand for the facilitation of this study and enthusiastic co-ordination. This work was supported by an exchange between MAPAQ and IFREMER (Fleury-Nadeau) and by funds from the Reseau Aquacole de Québec and from NSERC to HG.

\section{LITERATURE CITED}

Bailey, D. M., L. S. Peck, C. Bock \& H.-O. Pörtner. 2003. High Energy Phosphate metabolism during exercise and recovery in temperate and Antarctic scallops: an in vivo ${ }^{31}$ P NMR study. Physiol. Biochem. Zool. 76:622-633.

Barbeau, M. A. \& R. E. Scheibling. 1994. Behavioral mechanisms of prey size selection by sea stars (Asterias rubens Verrill) and crabs (Cancer irroratus Say) preying on juvenile sea scallops (Placopecten magellanicus (Gmelin)). J. Exp. Mar. Biol. Ecol. 180:103-136.

Brokordt, K. B.. J. H. Himmelman \& H. Guderley. 2000a. Effect of reproduction on escape responses and muscle metabolic capacities in the scallop Chlamys islandica Müller 1776. J. Exp. Mar. Biol. Ecol. 251: 205-225.

Brokordt, K. B., J. H. Himmelman, O. Nusetti \& H. Guderley. 2000 b. Reproductive investment reduces recuperation from escape responses in the tropical scallop Euvola ziczac. Mar. Biol. 137:857-865.

Brokordt, K. B. \& H. Guderley. 2004a. Energetic requirements during gonad maturation and spawning in scallops: sex differences in Chlamys islandica. J. Shellfish Res. 23:25-32.

Brokordt, K. B. \& H. Guderley. 2004b. Binding of glycolytic enzymes in scallop adductor muscle is altered by reproductive status. Mar. Ecol. Prog. Ser. 268:141-149.

Chantler, P. D. 1991. The structure and function of scallop adductor muscles. In: S. Shumway, editor. Scallops: biology, ecology and aquaculture. Developments in Aquaculture and Fisheries Science, vol. 21. Amsterdam: Elsevier. pp 225-304.

Cheng, J., I. Davison \& E. M. Demont. 1996. Dynamics and energetics of scallop locomotion. J. Exp. Biol. 199:1931-1946.

Chih, P. C. \& W. S. Ellington. 1983. Energy metabolism during contractile activity and environmental hypoxia in the phasic adductor muscle of the bay scallop Argopecten irradians concentricus. Physiol. Zool. 56: $623-631$.

Chih, P. C. \& W. S. Ellington. 1986. Control of glycolysis during contractile activity in the phasic adductor muscle of the bay scallop, Argopecten irradians concentricus: identification of potential sites of regulation and a consideration of the control of octopine dehydrogenase activity. Physiol. Zool. 59:563-573.

Fleury, P.-G., C. Mingant \& A. Castillo. 1996. A preliminary study of the behaviour and vitality of reseeded juvenile great scallops, of three sizes, in three seasons. Aquacult. Int. 4:325-337.

Fleury, P.-G., E. Croguennec, S. Pennec \& J. Maguire 1997. A muscle strength recorder ("Muscle meter") for quantifying juvenile scallop vitality 11 th International Pectinid Workshop April 10-15, 1997, La Paz Mexico. pp 7-9.

Gade, G., E. Weeda \& P. A. Gabbott. 1978. Changes in the level of octopine during the escape responses of the scallop, Pecten maximus (L.). J. Comp. Physiol. 124:121-127.

Lafrance, M., H. Guderley \& G. Cliche. 2002. Low temperature, but not air exposure slows the recuperation of juvenile scallops, Placopecten magellanicus from exhausting escape responses. J. Shellfish Res. 21:605618.

Legault, C. \& J. H. Himmelman. 1993. Relation between escape behaviour of benthic marine invertebrates and the risk of predation. J. Exp. Mar. Biol. Ecol. 170:55-74.

Livingstone, D. R., A. de Zwaan \& R. J. Thompson. 1981. Aerobic metabolism, octopine production and phosphoarginine as sources of energy in the phasic and catch adductor muscles of the giant scallop Placopecten magellanicus during swimming and the subsequent recovery period. Comp. Biochem. Physiol. 70B:35-44.

Maguire, J. A., P.-G. Fleury \& G. M. Burnell. 1999. Some methods for quantifying quality in the scallop Pecten maximus (L.). J. Shellfish Res. 18:59-66.

Manuel, J. L. \& M. L. Dadswell. 1991. Swimming behaviour of juvenile giant scallop Placopecten magellanicus, in relation to size and temperature. Can. J. Zool. 69:2250-2254.

Marsh, R. L., J. M. Olson \& S. K. Guzik. 1992. Mechanical performance of scallop adductor muscle during swimming. Nature 357:41 1-413.

Marsh, R. L. \& J. M. Olson. 1994. Power output of scallop adductor muscle during contractions replicating the in vivo mechanical cycle. I. Exp. Biol. 193:139-156.

Olson, J. M. \& R. L. Marsh. 1993. Contractile properties of the striated adductor muscle in the bay scallop Argopecten irradians at several temperatures. J. Exp. Biol. 176:175-193.

Thompson, R. J., D. R. Livingstone \& A. de Zwaan. 1980. Physiological and biochemical aspects of valve snap and valve closure responses in the giant scallop Placopecten magellanicus. I. Physiology. J. Comp. Physiol. 137:97-104.

Wilkens, L. A. 1981. Neurobiology of the scallop. I. Starfish mediated escape behaviours. Proc. R. Soc. Lond. B. Biol. Sci. 211:341-372.

Zwaan De, A., R. J. Thompson \& D. R. Livingstone. 1980. Physiological and biochemical aspects of the valve snap and valve closure responses in the giant scallop Placopecten magellanicus. II. Biochemistry J. comp. J. Comp. Physiol. 137:105-114. 